\title{
Introduction: clinical guidelines and the law of medical negligence
}

\section{Ash Samanta and Jo Samanta}

According to Montrose, the central question of negligence concerns 'what ought to be done in the circumstances, not what is done in similar circumstances by most people or even by all people'. ${ }^{1}$ He clarifies further that 'what ought to be done' is a normative, ethical concept compared to that what is done, which is a sociological concept. The key test for negligence is therefore an ethical, rather than sociological, construct. It is certainly the situation that what is done generally in practice might well not conform to the standard expected by a reasonable person, and in these circumstances it is not sufficient to state simply that a defendant acted in accordance with the generality of practice, and that careless conduct is therefore excusable.

It is axiomatic that in medical negligence the test for breach of duty of care is enshrined in the Bolam ${ }^{2}$ principle. Nevertheless, this landmark authority is now almost 70 years old. Over the ensuing decades the practice of medicine has changed irrevocably and the number of clinical interventions has increased exponentially. The demography and clinical complexity of cases has also altered. Moreover, society itself has moved on. With each generation people, as a whole, tend to be more knowledgeable with considerably higher expectations of medical practice.

The Bolam principle, as the yardstick against which to measure the standard of care in clinical (medical) negligence was articulated by McNair J as: 'A doctor is not guilty of negligence if he has acted in accordance with the practice accepted as proper by a responsible body of medical men skilled in that particular art.' ${ }^{3}$ Expanding on the same, he continued that a practice would not be negligent 'merely because there [was] a body of opinion that [took] a contrary view'. ${ }^{4}$ Taken together, these two statements appear to have created

\footnotetext{
1 JL Montrose, 'Is negligence an ethical or sociological concept?' (1958) 21 MLR 259-64.

2 Bolam v Friern Hospital Management Committee [1957] 1WLR 582.

3 Ibid., at 122.

4 Ibid.
} 
a traction for judicial determination, not only in the UK but also in some other jurisdictions, that inhibits proper scrutiny of medical conduct that is supported by peers as being customary practice - the so-called 'Bolam test'.

The net result is that the Bolam test is understood to have two key elements: first, doctors (in common with other professional groups more generally) are judged by the standards of their peers. This standard is underpinned by what is regarded as 'accepted practice' or 'customary practice'. Second, given that there are differing schools of thought, doctors cannot be held negligent if their conduct falls within a range of acceptable practice that is relevant at any given time. It is the second part of the Bolam test that has come under criticism and has been seen as over-deference of the court to medical opinion. ${ }^{5}$ Bolam has been viewed as being legitimately applied to technical areas of clinical practice such as diagnosis and treatment, but then pervasively overreaching into areas determined by best interests such as involuntary sterilisation decisions, ${ }^{6}$ and withdrawal of life support in cases of prolonged disorders of consciousness. The Bolam test has been seen as a matter for the medical profession to determine the legal standard expected in clinical practice and until recently the courts have shown reluctance to arbitrate between different schools of thought.

Academic commentators ${ }^{7}$ have long criticised the Bolam test as being overly paternalistic, and too deferential to expert medical opinion. Yet, probing of expert medical evidence by the court has never been proscribed. Shortly after the Bolam decision, Montrose suggested that from McNair J's premises, it followed that where a diverse range of practice was followed by professionals with a particular skill, then conformity with one of those practices would not be evidence of negligence. He also noted, somewhat presciently, that it would be going too far to suggest that McNair J had omitted entirely the possibility that a recognised practice could be negligent, and added that a necessary qualification to the Bolam principle was for the court to decide whether the ordinary practice of those possessed of a special skill was both reasonable and prudent. ${ }^{8}$ While in general terms conformity with one form of accepted practice will not equate to negligence, what is important is whether the particular form of practice was reasonable and prudent in relation to the circumstances, which is ultimately a matter for the court to decide.

5 H Teff, 'The standard of care in medical negligence: moving on from Bolam?' (1998) 18 OJLS 473-84.

6 Ibid., at 474.

7 Above, note 5.

8 Above, note 1. 
The advent of Bolitho ${ }^{9}$ served to initiate a shift away from the Bolam standard. Brazier and Miola took a stronger view in anticipating that Bolitho would herald a medical litigation revolution, and that it was time to say bye-bye to Bolam. ${ }^{10}$ A key question for the House of Lords in Bolitho was whether the Bolam test required a judge to accept without question truthful testimony from eminent experts. This proposition was rejected by their Lordships. The court was not bound to find for a defendant simply because of support from the evidence of a body of experts who believed genuinely that the defendant's practice was reasonable, responsible and respectable because it conformed to accepted practice. In the only substantive speech, Lord Browne-Wilkinson stated: 'The court has to be satisfied that the exponent of the body of opinion relied upon can demonstrate that such an opinion has a logical basis.' ${ }^{11}$ His Lordship's speech has been analysed in depth by a number of respected and erudite medical lawyers ${ }^{12}$ and is perceived generally as an attempt to correct what has been a misinterpretation of Bolam, as well as to reinstate that it is for the court to decide as to what constitutes reasonable care. Picking up on McNair J's statements in Bolam, the practice in question must be endorsed as proper by a responsible and reasonably competent body of professional opinion. In explicating on logical analysis, Lord Browne-Wilkinson spoke of weighing risks against benefits and that a judge would need to be satisfied that the experts had directed their minds to the question of comparative risks and benefits and reached a defensible conclusion on the matter. In sum, the court should take full cognisance of all relevant facts before making a finding as to the reasonableness of the defendant's conduct in the circumstances. It is unlikely Lord Browne-Wilkinson meant that expert medical testimony should be usurped by the court since, 'if in a rare case, it can be demonstrated that the professional opinion is not capable of withstanding logical analysis, the judge is entitled to hold that the body of opinion is not reasonable or responsible' ${ }^{13}$

Clinical guidelines are statements produced from the best available evidence. They are designed to assist clinicians to make optimal decisions about medical care, to promote consistency, and to narrow the variations in routine clinical practice. ${ }^{14}$ In clinical negligence litigation, where there is variance

9 Bolitho v City and Hackney Health Authority [1997] 3 WLR 1151; Bolitho [1998] AC 232 (HL) at 241-2.

10 M Brazier and J Miola, 'Bye-bye Bolam: a medical litigation revolution' (2000) 8 Med LR 85-114.

${ }_{11}$ Above, note 9, at 1159 .

12 Above, note 5 , note 10 .

13 Above, note 9, at 243 (emphasis added).

14 SH Woolf, R Groll, A Hutchinson, M Eccles and J Grimshaw, 'Clinical guidelines: potential benefits, limitations and harms of clinical guidelines' (1998) 318 British Medical Journal 527-30. 
between skilled professionals or experts then an objective set of standards, such as clinical guidelines, might assist the court in preferring one set of medical opinion over another when determining whether the defendant provided reasonable care in the circumstances.

The decisions of Bolam ${ }^{15}$ and Bolitho ${ }^{16}$ against other contextual change, prompted Brazier and Miola to state:

a host of other relevant developments affecting the provision of healthcare, suggests that in several contexts medical professional opinion would be subjected to rigorous scrutiny. An expert opinion, be it one on allegations of professional negligence, disclosure of risk, or the appropriate care of certain groups of patients, will no longer be determinative of professional obligations. In claims for medical negligence the emergence of sources of neutral and independent guidance on good practice will empower judges to utilise Bolitho and assess whether the opinion advanced by each party's experts is logical and defensible. ${ }^{17}$

It is against this background that we ask the question as to how clinical guidelines might engage with medical litigation.

In considering what might be the best way to explore the central theme of this book - clinical guidelines and the law of medical negligence - we formed the view that any study towards understanding this complex area would need to encompass a full visual frame of the relationship. While the existing literature has much to offer, this is confined mainly to the silos of either medicine, that addresses clinical guidelines, or within law where the focus is principally on negligence. There is little interaction between the two. There is also a paucity of academic discourse on the interface of these two entities, at the heart of which lies the question of the extent to which guidelines engage in determining the legal standard for breach of duty. This lack of connectivity has led to an information gap, as a result of which a nuanced understanding of the dyadic relationship between guidelines and medical negligence litigation is constrained. This is unsatisfactory for society as well as legal and medical practice.

To address this lacuna we have adopted a holistic approach to determine how guidelines are deployed in negligence litigation. In this volume we bring together a range of contributors from diverse backgrounds and specialisms in law as well as healthcare, who provide their perspectives, experience and knowledge of the use of guidelines at all stages of medical litigation. Contributors include legal academics, practising lawyers, practising clinicians and other health professionals, who offer a unique perspective on this area.

Above, note 2 .

Above, note 9 .

Above, note 10, at 113. 
The first four chapters provide a critique of how clinical guidelines have been used in case law and the fifth forms a link between guidelines and ethics at the interface of medical practice. The following four chapters are based on professional experience and viewpoints of practitioners: a barrister, solicitor, anaesthetist intensivist and an orthopaedic surgeon. In the final chapter we consider guidelines in litigation from a contemporary international perspective; then in the conclusion we propose a framework for the engagement of guidelines in litigation, based upon theory and the principle of reasonableness which is the cornerstone of negligence.

The chapters on the use of guidelines in South Africa, the Netherlands and the UK, as well as an Anglo-American comparison and a global overview of guidelines in litigation, cover wide ground and infuse an international flavour to the academic and practitioner-based narratives of this edition. The contributors have collaborated in weaving a rich multifaceted tapestry and, below, we provide a sample of some core issues from each chapter.

\section{THE EARLY USAGE OF CLINICAL GUIDELINES IN MEDICAL NEGLIGENCE LITIGATION: AN ANGLO-AMERICAN PERSPECTIVE}

Ash Samanta and Jo Samanta consider the development of evidence-based medicine in the UK around the start of the millennium and the ensuing production of evidence-based clinical guidelines. They consider the inception of guidelines at a time of change through sociopolitical drivers, such as the National Institute of Health and Care Excellence, regulators for healthcare, and the Government agenda for imposing a statutory duty of quality on the National Health Service. Production and dissemination of clinical guidelines had been gathering momentum in the UK around the end of the 1990s and had been used primarily in clinical settings to a limited degree. However, in US medical malpractice litigation they had been deployed for at least 20 years previously used either as a 'shield' as a defence against liability or as a 'sword' against defendants for either following or deviating from established guidance. Data from empirical research, along with a comparison of the use of guidelines within US case law litigation, provide an interesting backdrop for demonstrating how guidelines in litigation started in the UK and how this has developed over nearly two decades, especially as their data indicated that there was an expectation among solicitors and barristers that the usage of guidelines in medical negligence litigation would increase in the future. 


\section{RELIANCE ON CLINICAL GUIDELINES IN CONTEMPORARY NEGLIGENCE LITIGATION IN THE UK: INFLUENTIAL OR DETERMINATIVE?}

Rob Heywood considers the recent treatment of guidelines by judges in the UK and focuses on a number of contentious legal issues arising from their use in recent case law. He questions whether clinicians' conduct in relation to guidelines has received the appropriate level of scrutiny and whether compliance with guidelines should lead to a prima facie inference of no liability. Heywood argues that there is an ever increasing role of guidelines in the provision of modern healthcare and yet there has been uncertainty surrounding the precise status that should be afforded to them from a legal perspective. It is difficult to predict the amount of influence guidelines will have on allegations of negligence pertaining to treatment and diagnosis. As a result, a number of tensions flow not least from the fact that there are contradictions between the amount of emphasis placed on guidelines across different areas, which creates confusion among clinicians, patients and lawyers. There seems to be an emerging pattern that favours defendants over claimants, justified principally on the basis of the exercise of clinical discretion. A more proactive approach may be required from a judge to evaluate and interpret guidelines, and policies regarding this should be considered in determining negligence of the defendant. A further component of his analysis converges on the role of guidelines on information disclosure. Consent guidelines have played a significant role in developing the legal standard of disclosure as seen from the UK Supreme Court judgment in Montgomery $v$ Lanarkshire.

\section{MEDICAL GUIDELINES IN SOUTH AFRICAN COURTS: EXPLORING THEIR ROLE IN MEDICAL NEGLIGENCE MATTERS}

Camilla Pickles presents an interesting analysis of the South African courts' approach to clinical guidelines in medical negligence litigation. She begins with the idea that it is likely that guidelines hold some value in law within South African jurisdiction because various healthcare providers have been found negligent for failing to comply with these. She explores this regarding the role of guidelines in the context of reasonable foreseeability and preventability of harm, while linking this to limited resources, conflicting medical opinions, a variance of position between health professionals regarding guidelines and the acceptability of foreign medical guidelines in South African law. She argues that, in some situations, South African courts show an undue deference to the privileged position of doctors in society and medical knowledge, thereby 
displaying a reluctance to find negligence in some cases where guidelines have been ignored. Pickles offers an overview of South African common law and asserts that there is some value of guidelines in the field of clinical negligence. She explores some of the underlying issues that might impact on decision-making. However, in some instances the court may be swayed by the position of doctors holding a form of authoritative knowledge, thereby moving to avoid a finding of negligence where guidelines have been ignored.

\section{FITNESS TO PRACTICE TRIBUNALS IN THE UK AND THE NETHERLANDS: THE CONSTRUCTION OF (PARA)MEDICAL COMPETENCE AND THE USE OF EVIDENCE-BASED GUIDELINES}

Friso Jansen examines the work of fitness to practice tribunals by contrasting the fitness to practice tribunal for the Health and Care Professions Council (HCPC) in the UK and the National Medical Tribunals of the Netherlands. Previously, the literature has focused mainly on medical tribunals (such as the General Medical Council in the UK). This chapter considers the HCPC, which is the relatively new statutory regulator of 15 health and care professions, and contrasts this with the Dutch medical tribunals. A qualitative analysis of a sample of decisions by both tribunals is taken for comparative purposes. Jansen argues that there are subtle differences in institutional positioning and the structure of these tribunals and uses this to explicate the potential role of guidelines in informing the construction of competence for health professionals, as well as exploring differences and similarities between two national systems. These differences are highlighted, analysed and explained, thereby illustrating that, fundamentally in the UK, removal of negligent professionals is the primary aim thereby protecting the public from harm. In the Dutch system the aim of general improvement of medical practice through regulatory processes carries greater weight. Jansen demonstrates, by means of a comparative analysis, that there are two contrasting models wherein guidelines may be used. The first is one for making judgements about individual performance and the second is one to assess competence based upon guidelines being used to set the norm more generally. Medical guidelines have some relevance to the construction of competence for Dutch tribunals, but the English HCPC tribunal in contrast operates more through its internal regulatory rules.

\section{THE INTERFACE BETWEEN CLINICAL GUIDELINES AND HEALTHCARE ETHICS}

Marwan Habiba provides a view of evidence-based guidelines through the prism of a consultant gynaecologist and obstetrician who offers an alternative 
view that much of medicine is best practised through experience. While recognising the value of evidence-based medicine, he asserts that there is truth in the concept of an evidence-base because medicine should be based on 'evidence'. He argues that much of what has been learnt in medicine has been through observation and reasoning, and takes the position that the so-called 'traditional' medical approach is also built upon evidence, although perhaps not the type that represents the pinnacle of the modern 'scientific evidence-base'. In support of his argument he uses guidance for gynaecological conditions, and argues that this may limit various options for patients and could be detrimental in the longer term. He further considers the tensions that may arise at the point of applying research evidence to an individual patient and the difficulties underlying extrapolation of pooled generalised results to individual patient circumstances. Habiba's critique highlights potential biases, ethical tensions and pitfalls that may be inherent in indentured adherence to guidelines in clinical practice because of the prominence of their resonance and interdependency with managerialism. For this reason, guidelines work primarily as leverage for the exercise of political or institutional objectives.

\section{A BARRISTER'S EXPERIENCE OF THE USE OF CLINICAL GUIDELINES IN CLINICAL NEGLIGENCE LITIGATION}

Pritesh Rathod draws upon experiences from his own practice at the English Bar as a specialist in the field of clinical negligence to argue that the importance of clinical guidelines in clinical negligence litigation is variable. He suggests that their relevance is perhaps greatest where matters of clinical judgement are called into question. Examples are given and analysed to provide a deeper insight into this area. Based upon an examination of case law, and drawing from his own experience, Rathod suggests that in practice there is a hierarchy of guidelines and that local guidelines may at times be considered far more important and persuasive than higher level national guidance in cases of clinical negligence. He asserts that there is a growing trend by the court to look behind clinical decision-making in order to understand its rationale and an increase in the level of scrutiny by the court. With regard to the question of using clinical guidelines as a proxy for standard of care, Rathod concludes that guidelines should be used flexibly in order to inform the standard of care rather than to set it. 


\section{THE ROLE OF GUIDELINES AND PROTOCOLS IN CLINICAL NEGLIGENCE LITIGATION: A SOLICITOR'S VIEWPOINT}

Laurence Vick reflects on his experience as a practising solicitor over a period of 35 years, specialising in clinical negligence litigation for claimants. He notes the increasing use of guidelines that he has witnessed during this time but concludes, nonetheless, that their impact on clinical negligence remains difficult to assess because it can take several years for complex contested cases to come to trial. As the number of reported cases increase, there is an expectation that there should be less uncertainty about how guidelines will be interpreted in the court, as well as the force and weight that they might carry. Vick provides several examples showing how guidelines or protocols have been used, as well as a narrative of guidelines in the cardiovascular field that have generated controversy and have been shown to reflect a gender disparity in respect of the underlying research into the diagnosis and treatment of cardiac disease in women. He highlights the influence and growing impact of social media on initiatives for disseminating ideas that may not necessarily be guidelines, and concludes that lawyers need to be alive to the potential for challenging the validity of guideline evidence when offered in court.

\section{EVIDENCE-BASED MEDICINE, CLINICAL GUIDELINES, TRUSTWORTHINESS AND SAFE CARE IN ANAESTHETICS}

Rebecca Parrott and Debashish Dutta provide an analysis of clinical guidelines in litigation from the perspective of clinical practice in anaesthesia. Using the specialism of anaesthetics as an exemplar, the authors argue for a fine balance in the part played by guidelines. Anaesthetics is a specialty where it might be hard to either prove or disprove negligence without the aid of available robust guidelines. Equally, there is concern that blindly following guidelines may lead to deskilling of practitioners, which in itself is disadvantageous for good patient care. They argue that a systematic approach of considering safety issues in the process of clinical care in anaesthetic delivery significantly improves patient outcomes. Hence, safety and quality guidelines dominate in this specialty and are seen as positive and useful in providing a 'safety shell' for both clinicians and patients. However, there are many aspects of anaesthetic practice that have evolved through clinical experience and expertise. In these circumstances guidelines may not be necessarily underpinned by hard science and are formed through consensus opinion. The authors explore the meaning of what constitutes 'trustworthiness' in guidelines and expand on the 
potential tension between this concept and providing safe care, with exemplars from anaesthetics and critical care medicine. They conclude that it is important to streamline and standardise the process by which research and experiential evidence are used in creating a guideline, in order to assure safety within a clinical environment and validity of the guideline in the event of litigation.

\section{CLINICAL GUIDELINES IN TRAUMA AND ORTHOPAEDIC SURGERY}

Simon Britten provides a perspective of the use of clinical guidelines in determining the standard of care provided in cases of clinical negligence pertaining to trauma and elective orthopaedics surgery. There are many sources from which guidelines can be obtained for clinical work in this specialty when making decisions about treatment, as well as when considering the standard of care from a legal perspective. Orthopaedic surgeons must take into account not only guidelines but also circumstances specific to individual cases. He discusses this in the context of preoperative consent and draws upon examples from orthopaedics and other fields which have progressed to litigation. He argues that rigid adherence to guidelines may not always fit the special circumstances of a case and intentional deviation may be acceptable if doing so is reasonable in that instance. Britten raises a novel point regarding potential negligence during the Covid-19 pandemic when orthopaedic surgeons were removed from their sphere of specialism and redeployed to other areas of clinical practice, in order to support unforeseen and overwhelming clinical requirements during the crisis.

\section{A GLOBAL PERSPECTIVE OF THE USE OF CLINICAL GUIDELINES IN MEDICAL NEGLIGENCE LITIGATION}

Jo Samanta and Ash Samanta begin with the premise that clinical guidelines can be very useful for health professionals and may also have a role in determining the expected standard for determining breach of duty. In so doing, they consider contentious areas such as clinical guidelines being regarded as 'quasi law' and whether guidelines should be allowed to codify the norm. There are multiple confounding factors that might play a role in diminishing the value of guidelines. These could be lack of inclusion of specific groups of patients within the underpinning research data set, and potential conflicts of interest in the development of guidelines. The principal problematic issue that can affect the legal status of guidelines is the inherent tension between customary care that reflects standard practice, and care advocated by guidelines that are derived from a composite amalgamation of data from clinical trials. The authors review guidelines from an international perspective and consider their 
role in determining the legal standard. This varies considerably between different countries and they provide commentary and case law from several nations including the US, Canada, South Africa, Italy, Australia, Israel and India. The authors provide narrative on the growth and acceptance of guidelines internationally through the Guidelines International Network and various guideline appraisal tools. They speculate that this will continue to expand, particularly with supercomputers, and advancing technology that encompasses artificial intelligence. They conclude by stating that this trend for embracing guidelines on an international scale is laudable. However, they caution against rigid use as this may not be in the interests of patients, or litigants, in the longer term.

In this text, we have brought together a number of diverse views on the use of clinical guidelines in determining the legal standard for breach of duty. We have done this by inviting authors from a range of disciplines - professionals from academic law, as well as practitioners in law and medicine - to provide their views. We hope that this might furnish the reader with an array of ideas and perspectives to show that while guidelines are not dispositive in medical negligence litigation, they do nonetheless have a role to play which would seem to be increasing over the years. A balance must be struck between slavish reliance on guidelines and having no regard for them at all. In our conclusion we return to the enduring pertinence of the vision of the key to negligence within the register of the late James Montrose - the question is one of what ought to be done in the circumstances, not what is done in similar circumstances. We assert that guidelines can be used most fruitfully if their application is tempered with reasonableness to the particular circumstances of each case. We offer a framework for reasonableness in using clinical guidelines for determining the legal standard of care, and illustrate its application with case-based discourse. We hope that our efforts may add value to how guidelines may be used most effectively within the law of medical negligence. 